\title{
Habilidades directivas y diferencias de género en el sector público: el caso de Córdoba (España)
}

\author{
Managerial skills and gender differences \\ in the public sector: The case of Córdoba (Spain)
}

FRANCISCO J. PEREDA-PÉREZ

Universidad de Córdoba

TOMÁS LÓPEZ-GUZMÁN

Universidad de Córdoba

FRANCISCO GONZÁLEZ-SANTA CRUZ

Universidad de Córdoba

\section{Cómo citar/Citation}

Pereda-Perez, F. J., López-Guzmán, T. y González-Santa Cruz, F. (2018). Habilidades directivas y diferencias

de género en el sector público: el caso de Córdoba (España). Revista Española de Ciencia Política, 46, $199-230$.

Doi: https://doi.org/10.21308/recp.46.09

\section{Resumen}

El presente artículo tiene como objetivo un acercamiento al análisis de las habilidades directivas y su valoración a nivel directivo y subordinado, a la vez que introduce una perspectiva de género. Se presentan las conclusiones de una investigación sobre las habilidades directivas en el sector público de Córdoba (España). A partir de una encuesta a funcionarios públicos realizada en las cuatro Administraciones presentes en Córdoba, los principales hallazgos sugieren que las personas empleadas en el sector público reconocen y valoran la eficacia en el desempeño profesional como el atributo más relevante, así como la capacidad de aprender y la colaboración y el trabajo en equipo. Los resultados muestran que las mujeres valoran y presentan mejores puntuaciones que los hombres respecto a las siguientes cualidades: constancia, iniciativa, organización/eficacia y cordialidad en el trato. Estos resultados ofrecen una perspectiva positiva sobre los avances que se están produciendo en el ámbito de la igualdad de género.

Palabras clave: habilidades directivas, sector público, empleados públicos, género, España. 


\begin{abstract}
This article aims to approach the analysis of managerial skills and their assessment at the managerial and subordinate level, introducing a gender perspective. The conclusions of a research on management skills in the public sector of Córdoba (Spain) are presented. Based on a survey to public officials carried out in the four administrations in Córdoba, the main findings suggest that people employed in the public sector recognize and value efficiency in professional performance as the most relevant attribute, as well as the ability to learn and collaboration and teamwork. The results show that women value and present better scores than men with respect to the following qualities: determination, initiative, organization/effectiveness and friendliness of treatment. These results offer a positive perspective on the progress being made in the field of gender equality.
\end{abstract}

Keywords: management skills, public sector, civil servants, gender, Spain.

\title{
INTRODUCCIÓN
}

Cuestiones sobre si hombres y mujeres emplean diferentes estilos de liderazgo siguen formulándose sin una respuesta definitiva, así como si esas diferencias explican la escasa presencia femenina en los puestos directivos, algo que resulta interesante tanto para el estudio académico como para el de la gestión. El género es un concepto utilizado para definir, representar y simbolizar las diferencias sexuales en una determinada organización o en la sociedad. Por tanto, alude a las formas históricas y socioculturales en que mujeres y hombres construyen su identidad, interactúan y organizan su participación en los diferentes ámbitos organizativos y sociales. Estas formas varían de una cultura a otra y se transforman a través del tiempo. El concepto de género se empleó por primera vez en el ámbito de la psicología médica durante la década de 1950. Sin embargo, no fue hasta 1968 cuando Robert Stoller la desarrolló en una investigación empírica sobre trastornos de la identidad. En este estudio, Stoller (1968) demostró que lo que determina la identidad y el comportamiento masculino o femenino no es el sexo biológico, sino las expectativas sociales, ritos, costumbres y experiencias que están asociadas al hecho de haber nacido mujeres u hombres. Por su parte, Rubin (1986) define el sistema sexo/género como el sistema de relaciones sociales que transforma la sexualidad biológica en productos de actividad humana.

En el ámbito de las organizaciones, en la actualidad ya no es suficiente con mantenerse y subsistir como empresa, sino que se requieren nuevos instrumentos, entre ellos las habilidades para poder generar procesos de toma de decisiones con las garantías adecuadas de una permanente adaptación a las situaciones a las que se enfrentan. Este es el reto para el futuro, por lo que las organizaciones en general han ido evolucionando debido a que a nivel mundial se han generado cambios de distintos tipos: sociales, económicos, políticos, culturales, tecnológicos, entre otros (Werther y Davis, 
2008). Durante el siglo xx, el interés de las organizaciones estuvo centrado en cómo incrementar la productividad de estas procurando el bienestar del individuo (Gibson et al., 2001). En el ámbito del sector público, la revisión de la capacidad de los Gobiernos ha consistido en asumir que las Administraciones que cumplen una serie de requisitos y son más activas en la introducción de reformas en la gestión de una serie de áreas (presupuesto, personal, inversiones, contratación, administración electrónica) son más efectivas y alcanzan un mayor rendimiento (Ballart, 2010).

Sin embargo, como señala Alas (2007), las organizaciones no son únicamente medios para proveer de bienes y servicios a la sociedad. En todas ellas interactúan personas, hombres y mujeres, cada una de ellas con sus capacidades y motivaciones. Personas que interactúan con otras personas para lograr resultados a través del trabajo en equipo, la colaboración y el liderazgo. En este sentido, los recursos humanos se han convertido en clave de la competitividad de las organizaciones, tanto privadas como públicas (Rosa Navarro y Carmona Lavado, 2010).

Peters y Waterman (1982), quienes incluyeron las habilidades (skills) entre las siete variables fundamentales que identifican a las organizaciones de éxito, advirtieron que el liderazgo se confundía con la capacidad de garantizar la excelencia de una organización, pues solo ella aseguraba la competitividad y los buenos resultados. Pero más allá de los indicadores propiamente económicos, la presión por la excelencia generó otros fenómenos, seguramente no deseados, pero que eran resultado de los incentivos y valores postulados. Dos de estos fenómenos son particularmente destacados e interesan en el análisis de las habilidades directivas que se abordan en esta investigación.

A pesar de los progresos realizados en los últimos años, las estadísticas muestran que la presencia de mujeres en puestos directivos está aún lejos de ser igual a la de los hombres, situación que aumenta progresivamente al subir en la pirámide organizacional. Concretamente, las mujeres representan un $12,3 \%$ de los miembros de los consejos de administración de las principales empresas que cotizan en la bolsa española (índice IBEX 35). Esta proporción está por debajo de la media de la UE (15,8\%). El porcentaje de mujeres presidentes de consejos de administración y de consejeras delegadas en España $(2,9 \%)$ está cerca de la media de la UE en ambos casos (Comisión Europea, 2012).

En cambio, esta realidad de la mujer en la sociedad y en la empresa choca con sus habilidades, capacidades y competencias, muchas veces con un nivel superior a los hombres. Efectivamente, las mujeres allá donde han podido desarrollar sus habilidades han sabido estar a la altura de las expectativas. $Y$ estas habilidades, en general, y las directivas, en particular, ofrecen una perspectiva decisiva como atributo personal que supera cualquier discriminación.

Un enfoque distingue entre las desigualdades derivadas de características individuales tales como el nivel de educación, las destrezas, la antigüedad y las desigualdades debidas a la discriminación. Un segundo enfoque se centra en las desigualdades entre grupos y observa que los salarios de las mujeres en determinadas ocupaciones, sectores, destrezas o niveles de pensión son típicamente menores que los de los 
hombres con independencia de las habilidades individuales. Este enfoque argumenta que estas desigualdades solo pueden ser explicadas por la discriminación (OIT, 2003: 47). En este sentido, la importancia de las habilidades y competencias queda patente en investigaciones (Cuadrado et al., 2004; Paustian-Underdahl et al., 2014), en donde se constata que las mujeres valoran en mayor medida las habilidades directivas que los hombres.

Esta investigación tiene como objetivo, por una parte, destacar la importancia de las habilidades directivas como variables imprescindibles en las organizaciones, de manera específica en la públicas; por otra, encontrar en el género diferencias significativas sobre la percepción y valoración de atributos profesionales y habilidades directivas. Se considera relevante en cuanto que trata de abordar una realidad, la valoración de las habilidades directivas, en un contexto muy amplio y completo -las cuatro Administraciones públicas en una provincia española- a partir de una significativa muestra de mujeres y hombres que trabajan en dicho sector. El presente artículo contribuye al debate sobre las diferencias entre hombres y mujeres en las habilidades directivas desplegadas en un contexto específico, pero a la vez muy amplio: las organizaciones públicas.

Se analizan las actitudes de los trabajadores del sector público respecto a las habilidades directivas en su sector, centrándose en las diferencias de género. Se considera que su relevancia social es destacada, tanto por el sector económico en cuestión (el público), como por el componente (las habilidades), que ocupa un lugar de máxima importancia en el desempeño profesional, así como por la perspectiva de género que incorpora, aspecto de gran actualidad en la sociedad, que demanda avances en el conocimiento de una realidad sometida a vertiginosos cambios.

Los principales hallazgos empíricos que aporta la presente investigación tienen que ver con la identificación de la eficacia en el desempeño profesional como el atributo más relevante que debe tener un «buen empleado» público. Además, la capacidad de aprender y la colaboración y el trabajo en equipo son las habilidades directivas que mayor valoración reciben tanto por hombres como por mujeres en puestos directivos, mientras que en los puestos subordinados los hombres valoran más la capacidad de comunicación y las mujeres la capacidad de aprender. Por último, los resultados muestran que las mujeres valoran y presentan mejores puntuaciones que los hombres respecto a las siguientes cualidades: constancia, inicaciativa, organización/eficacia y cordialidad en el trato. En este sentido nuestra aportación a la literatura científica especializada consiste en un acercamiento a la complejidad de las organizaciones del sector público a partir de las habilidades directivas, elemento decisivo para entender el el desarrollo de las organizaciones.

La estructura de este artículo consta, tras la presente introducción, de una revisión teórica sobre el tema, para continuar con un apartado dedicado a la descripción del estudio de caso. Posteriormente, se ofrecen algunas consideraciones sobre la metodología aplicada y se revisan los principales resultados del estudio. Se finaliza el artículo con las conclusiones más relevantes, que persiguen avanzar en el conocimiento científico sobre la materia objeto de estudio. 


\section{REVISIÓN DE LA LITERATURA}

En Europa se han producido en las últimas décadas cambios importantes en la maquinaria que se ocupa del género y otras desigualdades de los Estados miembros. Las agencias a cargo de las políticas para las mujeres se ven afectadas por procesos externos de gobernanza, globalización, regionalización, privatización y reforma del Estado de bienestar (Lombardo y Verloo, 2010).

\section{Habilidades directivas y estilos de liderazgo}

La importancia de las habilidades directivas en el sector público ha sido un tema que ha suscitado mucho interés, como así lo corrobora los resultados de esta investigación. En este sentido, en las organizaciones modernas para formar un equipo directivo hay que tener en cuenta las competencias directivas, y para definir su composición ideal es necesario describir las funciones, competencias y habilidades requeridas para el desempeño eficaz del trabajo directivo. Aunque las funciones, competencias o habilidades directivas no son exclusivas de un sexo u otro, determinadas características se atribuyen en mayor medida a los hombres, mientras que otras a las mujeres. De acuerdo con los estereotipos de género, entendido como un conjunto de creencias compartidas socialmente acerca de las características que poseen hombres y mujeres, se establece una clasificación de las funciones, habilidades y competencias como fundamentalmente masculinas o femeninas. Por tanto, del análisis de las competencias requeridas y su rango de masculinidad y/o feminidad se obtiene un factor que representa la proporción de hombres y mujeres que deben formar parte del equipo de dirección. Este factor se denomina "perfil de diversidad del puesto» (Barberá Heredia, 2004). Este autor considera a los individuos como personas en su totalidad (con sus habilidades, aspiraciones y necesidades).

Sin embargo, el perfil actual de la gran mayoría de organizaciones dista mucho de ser diverso, sobre todo en sus niveles superiores de responsabilidad y toma de decisiones. La actual cultura y políticas organizacionales tienden a la creación de entornos no inclusivos de la diferencia humana, dando lugar a equipos homogéneos mayoritariamente masculinos, lo cual, a largo plazo, provoca ineficacia y pérdida de competitividad y adaptación a la sociedad global actual (Barberá Heredia, 2004).

En relación con la responsabilidad social corporativa y los efectos sobre la percepción de género, se ha demostrado que factores como la diversidad de genéro en la dirección y el liderazgo de inclusión de género tienen un impacto positivo sobre el nivel y la calidad de la responsabilidad social y, por extensión, sobre el rendimiento y la sostenibilidad financiera de las corporaciones (Courtney Droms y Sheryl-Ann, 2015).

Investigaciones como la de Molero Alonso (2009) muestran que el liderazgo eficaz no está ya asociado únicamente a características típicamente masculinas, sino que cada vez se asocia más a características propias del estereotipo femenino, en la línea de los resultados obtenidos en la investigación realizada. Este hecho se observa tanto respecto 
a cuáles son las características que debe tener un directivo (hombre o mujer) para tener éxito como, y lo que es más importante, en las evaluaciones reales que los participantes hacen de sus jefes y jefas. En esta línea apuntan Burke y Collins (2001) en su investigación sobre diferencias de género en los estilos de liderazgo y las habilidades directivas ofreciendo resultados que confirman una mayor efectividad percibida por las mujeres en determinadas habilidades directivas, como el desarrollo de personas y la capacidad de comunicación.

Existen estudios en materia de liderazgo que revelan, siguiendo a Sánchez Apellániz (1997), que la manera de pensar, sentir y actuar de las mujeres es diferente y que por ello puede hablarse de un estilo de dirección diferente que se caracteriza por el énfasis en las personas y los procesos, el liderazgo como responsabilidad de todos, la constitución de estructuras menos burocratizadas, priorizando las relaciones sociales y el sentido de comunidad, el «dejar hacer» potenciando profesionalmente a los colectivos a través de sus propios conocimientos e ideas y una clara preferencia por los enfoques cooperativos y consultivos. En este sentido, Berbel Sánchez (2014) considera que las diferencias culturales dan lugar a aprendizajes y entrenamientos diferentes, tanto en cuanto a las aptitudes que se desarrollan como en relación con la construcción de la personalidad.

En sus investigaciones, Eagly y Johnson (1990) indican que los hombres manifiestan un estilo de mando más autocrático y que el de las mujeres es más democrático y orientado a lo interpersonal: se muestran solícitas, amigables, accesibles, dispuestas a explicar los procedimientos e interesadas por el estado de ánimo y el bienestar de los demás. Esta importante aportación es confirmada por nuestra investigación en el sector público, al obtenerse una mayor valoración en las mujeres, como directivas y subornidadas, en la habilidad directiva colaboración y trabajo en equipo. En esta línea, Kabacoff (1998) descubrió que las mujeres suelen obtener mejor calificación que los hombres en empatía (mostrar una preocupación activa por las personas y sus necesidades, formar relaciones estrechas de apoyo con otros) y comunicación (formular con claridad lo que esperan de los demás, exponer claramente pensamientos e ideas, mantener una corriente de comunicación). También se las considera superiores en capacidad de trato humano (sensibilidad para con los demás, simpatía, saber escuchar y establecer relaciones fructíferas con sus iguales y con aquellos a quienes deben rendir cuentas).

\section{Mujeres y sector público}

A pesar de los avances en materia de igualdad de género en la participación en el mercado de trabajo, sigue vigente la brecha en la división sexual del trabajo. Efectivamente, la disparidad se ha reducido por el descenso de la natalidad, de la edad de gestación y de la familia, por el aumento de mujeres independientes, por la progresiva participación de los hombres en las tareas domésticas y por la erosión de la familia nuclear, que proporcionaba recursos y seguridad; también por las presiones económicas para sostener determinado estilo de vida (Giddens, 2001). 
No obstante, la división sexual del trabajo «ha reservado a la mujer los puestos más alejados del poder de decisión y prolongado los hábitos hogareños, adjudicándole las tareas asimilables y más rutinarias, menos creativas y escasamente valoradas» (De la Cruz, 2006: 274). Es cierto que en la actualidad se demanda mujeres en la esfera pública y hombres en la privada. Pese a esto, el supuesto equilibrio y complementariedad se sigue dando en términos de desigualdad (Moncayo Orjuela y Villalba Gómez, 2013). Estos autores concluyen que el desarrollo de habilidades en liderazgo llevado a cabo bajo esquemas educativos tradicionales, basados en modelos organizativos obsoletos, impide que se forjen los líderes que hoy en día requiere la sociedad contemporánea. Por otro lado, la socialización, comunicación, reproducción y promoción de patrones y estereotipos de género que producen los planteles educativos, parece tornarse un factor limitante fundamental para las mujeres a la hora de proyectar su horizonte profesional y laboral.

Bieger (2005) considera que las mujeres son muy parecidas a los hombres en lo que a habilidades directivas se refiere, destacando que un $48 \%$ de los hombres considera que son más impositivas que ellos; sin embargo, el $52 \%$ restante piensa lo contrario. Nuestra investigación también apunta a esta conclusión, aunque ofrece diferencias significativas de interés. Por su parte, Munduate (2003) afirma que al contrastar el rol de mujeres directivas con el de hombres directivos, era este último grupo el que más se aproximaba a las características identificadas como clave para el éxito en la función directiva, entendida como habilidad de liderazgo, ambición, competitividad, deseo de responsabilidad, maestría en asuntos de negocios, competencia y habilidad analítica.

Como apunta Wood (1992), puede que no existan muchas diferencias en el modo en que hombres y mujeres ejercen determinadas habilidades, como el liderazgo, gestión de conflictos o trabajo en equipo, etc., pero se vive en una sociedad marcada por el género, y las diferencias biológicas resultan cruciales para el modo en que son entendidas, vistas por los demás y sobre el modo en que son afrontadas por las propias mujeres. En la investigación realizada, las distintas valoraciones tambien confirman estan diferencias sobre detrminadas habilidades directivas. En este sentido, a pesar de la creencia de que los hombres suelen ser percibidos como más eficaces que las mujeres en el desarrollo de las habilidades de liderazgo, está tomando relevancia la posible existencia de una ventaja en el denominado liderazgo femenino (Cuadrado, 2014).

Paustian-Underdahl et al. (2014) muestran que los hombres y las mujeres no difieren sustancialmente en la eficacia del liderazgo percibido. Sin embargo, existen diferencias entre las valoraciones y las autovaloraciones, en el sentido de que las mujeres son valoradas como más eficaces que los hombres, mientras que cuando se examina la autoevaluación, los hombres se valoran a sí mismos como significativamente más eficaces que cuando las mujeres se autovaloran, por lo que el sexo, tanto del directivo como del subordinado, influyen en la percepción del liderazgo, así como su repercusión a nivel organizacional, lo que podría explicar la dificultad del acceso de las mujeres a los puestos directivos (Cuadrado et al., 2004).

La investigación sobre las diferencias en el trabajo directivo en función del sexo muestra que hombres y mujeres se diferencian en competencias (Strebler et al., 1997). 
Sin embargo, los estereotipos de género pesan en las percepciones y autopercepciones que tienen ambos sexos. Por su parte, Barbuto et al. (2007) muestran resultados en la línea de que el género produce un pequeño efecto directo sobre las conductas de liderazgo. En cambio, estudios como el de Letelier Gamboa (2014) sobre diferencias de género en los estilos de afrontamiento de conflictos de funcionarios en el ámbito de la salud pública, apunta diferencias de género notables en el sentido de que los hombres presentan un estilo competitivo y las mujeres un estilo colaborador. Otra importante diferencia radica en que los hombres presentan el estilo evitador y las mujeres el conciliador.

La psicología social ha destacado el papel de las creencias a través de los roles estereotipados, las actitudes prejuiciosas hacia las mujeres, la ideología sexista o el desarrollo de identidades de género, cuestión que se manifiesta en conductas determinadas que acaban teniendo influencia en las relaciones de poder en el ámbito laboral (Barberá Heredia et al., 2011). Es decir, la interpretación psicológica ha puesto de relieve que el género, a veces, se manifiesta a través de las conductas de hombres y las mujeres, pero también está presente en la interpretación que se hace de dichas conductas y, sobre todo, se observa en las reacciones que se generan en el transcurso de las relaciones interpersonales.

La diversidad de género en el liderazgo es necesaria para las organizaciones y, a la vez, un derecho de las mujeres. Respecto a las relaciones de poder, estos autores consideran que la percepción de las mujeres como posibles competidoras en el mercado del trabajo estimula la creencia sobre su falta de valía o de motivación personal. Este proceso ayuda a mantener la posición de dominio masculino. Las actitudes sexistas son la expresión de un conflicto entre los valores igualitarios y los sentimientos residuales negativos hacia las mujeres, a las que algunos hombres perciben como una amenaza respecto de sus intereses de grupo dominante en un entorno altamente competitivo.

En resumen, la ventaja comparativa de las habilidades de las mujeres respecto a los hombres para desarrollar tareas de dirección en el sector publico se pueden concretar en aspectos concretos como la inteligencia emocional (Goleman, 1996). Así, las mujeres tienen resultados notablemente mayores en dos de las competencias del autoconocimiento: mejor aprendizaje emocional, que significa saber identificar lo que se siente, y reconocimiento de patrones, que significa saber lo que se está haciendo con los sentimientos y como se reacciona automáticamente a cada emoción que se siente. Otras habilidades en las que las mujeres pueden ofrecer ventajas son las siguientes: capacidad de organización y planificación, capacidad de comunicación, conocimiento de la organización y creatividad.

Para que que estas ventajas se consoliden, es requisito imprescindible neutralizar el persistente estereotipo que asocia la dirección con el sexo masculino. Siguiendo a Jonsen y Maznevski (2010), es preciso explorar el papel de estos estereotipos sobre las creencias con respecto a la relación de género y habilidades directivas (Caro González et al., 2007), ya que la cultura influye sobre estas percepciones, y a su vez sobre las perspectivas sobre cómo podrían influir en las iniciativas de diversidad de género y en las prácticas de recursos humanos. 
La literatura denomina «techo de cristal» a las barreras invisibles que impiden a las mujeres llegar hasta los puestos más altos. En el sector público, la realidad que se observa es que cuanto más alta es la jerarquía institucional menos mujeres hay, a pesar de la alta formación que acreditan las mujeres en Espańa. La presencia de la mujer en los puestos de dirección aún está lejos de la paridad por factores como la menor conexión de la mujer profesional con las redes necesarias para progresar, la creencia de que una mujer es un riesgo para la empresa por sus obligaciones familiares y las dificultades debidas al perfil de los cargos directivos que exige largas jornadas y movilidad (OIT-PNUD, 2009).

\section{DESCRIPCIÓN DEL ESTUDIO DEL CASO}

La investigación se ha desarrollado en la provincia de Córdoba, que tiene una población de 790891 habitantes a 1 de enero de 2016 (Instituto Nacional de Estadística, 2016a). La capital de la provincia está situada en la ciudad de Córdoba, que reúne al 41,39 \% de la población total. Situada en el sur de Espańa, forma parte en la Comunidad Autónoma de Andalucía.

Desde la perspectiva económica, los sectores de actividad en la provincia de Córdoba tienen una significación propia, y destaca el sector servicios, que ha ido tomando importancia de forma progresiva a lo largo de décadas. Efectivamente, la composición sectorial revela una estructura productiva excesivamente dependiente del sector servicios, en el que se incluye al sector público. En la tabla 1 se muestra su destacada posición: según los últimos datos disponibles de 2015 (Instituto Nacional de Estadística, 2016b) el sector servicios alcanza el 70,94\% del PIB provincial. De este porcentaje cabe destacar que el sector publico de la provincia de Córdoba alcanza el 28,08\% de toda la actividad económica, frente al $18,74 \%$ en España.

TABLA 1.

DistribuCIÓN DE LA COMPOSICIÓN DEL PIB EN \%

\begin{tabular}{lcc}
\hline \multicolumn{1}{c}{ Sectores } & Córdoba & España \\
\hline Agricultura & 7,34 & 2,51 \\
\hline Industria & 15,12 & 17,03 \\
\hline Construcción & 6,60 & 5,53 \\
\hline Servicios & 70,94 & 74,92 \\
\hline
\end{tabular}

Fuente: Instituto Nacional de Estadística (2016b).

En cuanto a ocupación y tasa de paro (tabla 2), la provincia de Córdoba, según datos al segundo trimestre de 2016 (Instituto Nacional de Estadística, 2016c), muestra una tasa de actividad en mujeres del $51,15 \%$ frente al $65,94 \%$ en hombres, mientras que el desempleo representa el 32,28\%, frente al 28,40\% de los hombres. 
TABLA 2.

OCUPACIÓN Y PARO. TASAS DE ACTIVIDAD Y PARO POR SEXO

\begin{tabular}{lcccc}
\hline \multicolumn{5}{c}{ Valores absolutos en miles y tasas en porcentaje } \\
\hline \multicolumn{1}{c}{ Ambos sexos } & Ocupación & Paro & Tasa de actividad & Tasa de paro \\
\hline Córdoba & 266,7 & 115,1 & 58,34 & 30,15 \\
\hline Andalucía & 2832,7 & 1161,1 & 58,00 & 29,07 \\
\hline España & 18301,0 & 4574,7 & 59,41 & 20,00 \\
\hline Hombres & \multicolumn{5}{c}{} & \\
\hline Córdoba & 150,2 & 59,6 & 65,94 & 28,40 \\
\hline Andalucía & 1598,8 & 581,3 & 64,63 & 26,66 \\
\hline Espańa & 9971,1 & 2249,6 & 65,21 & 18,41 \\
\hline Mujeres & & & 32,28 \\
\hline Córdoba & 116,5 & 55,5 & 51,15 & 21,82 \\
\hline Andalucía & 1233,9 & 579,8 & 53,91 & \\
\hline Espańa & 8329,9 & 2325,1 & & \\
\hline
\end{tabular}

Fuente: INE (2016a).

Respecto al sector público, la provincia de Córdoba mantiene unos efectivos de 43709 empleados públicos a enero de 2016 (Ministerio de Hacienda y Administraciones Públicas, 2016), lo que representa un 9,49\% del empleo público andaluz y un $1,73 \%$ del empleo público total español. En la tabla 3 se recogen los datos disponibles sobre empleados públicos, con el desglose por tipo de Administración. Destaca la Administración autonómica con un 53,33\% del total (23 309 efectivos), seguido de la local con un 23,63\% y 10330 efectivos. A continuación se encuentra la Administración estatal con un $18,75 \%$ (8196 empleados) y, finalmente, la universitaria con un 4,29\% y 1874 efectivos. Destaca la elevada presencia de las mujeres en la Administración autonómica (debido a que estas Administraciones tienen asumida las competencias en sanidad y educación, actividades en las que las mujeres tienen una sobrerrepresentación), mientras que la Administración estatal ve reducida la presencia femenina notablemente (asume competencias como la seguridad y defensa, que mantiene aún mucho empleo público masculino). La tabla 3 también sugiere el ajuste que se está produciendo en los recursos humanos del sector público en los últimos años (2011-2015), que llega a alcanzar el 9,22\%, al buscar la optimización de recursos mediante el empleo más eficiente de los efectivos que trabajan en las diferentes Administraciones.

La provincia de Córdoba alcanza el 1,73\% de empleo público sobre el total español, por lo que comparativamente se trata de una provincia de dimensión intermedia, en donde destaca claramente Madrid, con el 15,50\% de todos los empleados públicos españoles, frente a Soria, provincia española con menos empleados públicos (7953, un 0,32\%). En Andalucía alcanza el ya indicado 9,49\%, muy por detrás de Sevilla 
Habilidades directivas y diferencias de género en el sector público: el caso de Córdoba (España) 209

TABLA 3.

EMPLEO PÚBLICO POR TIPO DE AdMINISTRACIÓN

\begin{tabular}{lccccc}
\hline \multicolumn{1}{c}{ Ámbito } & Estatal & Autonómica & Local & Universidad & Total \\
\hline Espańa & 527.801 & 1.294 .765 & 548.944 & 147.770 & $\mathbf{2 . 5 1 9 . 2 8 0}$ \\
\hline Hombre & 366.620 & 409.604 & 290.248 & 78.782 & $\mathbf{1 . 1 4 5 . 0 2 6}$ \\
\% & $(69,5)$ & $(31,6)$ & $(52,9)$ & $(53,3)$ & $\mathbf{( 4 5 , 5 )}$ \\
\hline Mujer & 161.181 & 885.161 & 258.696 & 68.988 & $\mathbf{1 . 3 7 4 . 0 2 6}$ \\
\% & $(30,5)$ & $(68,4)$ & $(47,1)$ & $(46,7)$ & $\mathbf{( 5 4 , 5 )}$ \\
\hline Córdoba 2016 & $\mathbf{8 . 1 9 6}$ & $\mathbf{2 3 . 3 0 9}$ & $\mathbf{1 0 . 3 3 0}$ & $\mathbf{1 . 8 7 4}$ & $\mathbf{4 3 . 7 0 9}$ \\
\hline \% Espańa & 1,55 & 1,80 & 1,88 & 1,27 & 1,73 \\
\hline \% Córdoba & 18,75 & 53,33 & 23,63 & 4,29 & 100,00 \\
\hline Córdoba 2011 & 8.930 & 25.692 & 11.457 & 2.080 & $\mathbf{4 8 . 1 4 9}$ \\
\hline Dif. 2011-2015 & $\mathbf{- 7 3 4}$ & $\mathbf{- 2 . 3 8 3}$ & $\mathbf{- 1 . 1 2 7}$ & $-\mathbf{2 0 6}$ & $\mathbf{- 4 . 4 4 0}$ \\
\hline \% variación & $-8,22$ & $-9,28$ & $-9,84$ & $-9,90$ & $-9,22$ \\
\hline
\end{tabular}

Fuente: elaboración propia a partir de datos del Ministerio de Hacienda y Administraciones Públicas (2016).

$(24,75 \%)$ y Málaga $(15,97 \%)$, aunque supera clramente a Huelva, provincia andaluza con menor número de empelados públicos $(6,54 \%)$.

En cuanto a género, los datos comparativos no muestran grandes diferencias: en Córdoba, la mujer ocupa el $48,77 \%$ de los empleos públicos, tasa prácticamente idéntica en Andalucía (48,73\%), pero ligeramente superior a la media española (45,25\%).

\section{METODOLOGÍA}

La investigación objeto de este trabajo se realizó mediante un estudio empírico centrado en el sector público de la provincia de Córdoba, que incluía una importante representación de entidades, siendo la población universo la totalidad de los empleados públicos. La muestra integraba unidades administrativas de las cuatro Administraciones con presencia en la provincia de Córdoba: estatal, autonómica, local y universitaria, elegidas para abarcar sectores diferentes, localizaciones geográficas y dimensiones distintas, lo que dada la composición del sector público no hubiera estado garantizado mediante la elección de una muestra aleatoria. El cuestionario fue respondido por empleados públicos, tanto empleados de base como por mandos intermedios o directivos, y se alcanzó una proporción del $40,2 \%$ en cuanto a los cuestionarios respondidos por personal directivo o mandos intermedios. Los datos se encuentran archivados en soporte físico en la Facultad de Derecho y Ciencies Económicas y Empresariales de la Universidad de Córdoba, así como en soporte digital en ficheros de la aplicación SPSS versión 21 para Mac. La tabla 4 proporciona información detallada del estudio: 
TABLA 4.

FiCHA TÉCNICA DE LA INVESTIGACIÓN

\begin{tabular}{ll}
\hline Ámbito geográfico & Provincia de Córdoba \\
\hline Universo & Personal del sector público \\
\hline Tamańo del universo & 46175 empleados públicos \\
\hline Modo de aplicación & $\begin{array}{l}\text { Presentación personal y cuestionario estructurado y cerrado } \\
\text { y mediante cuestionario online }\end{array}$ \\
\hline Tamańo de la muestra & 1363 cuestionarios contestados \\
\hline Error muestral & $2,62 \%$ \\
\hline Alpha de Cronbach & 0,854 \\
\hline Recogida de información & Septiembre-diciembre 2013 \\
\hline
\end{tabular}

Fuente: elaboración propia.

En relación con la medición de las habilidades directivas, los instrumentos de medida más frecuentemente utilizados son los cuestionarios, pues corresponden a la naturaleza multidimensional que ofrece la amplia variedad de habilidades personales, interpersonales y de dirección, que configuran la base de la actuación de un trabajador o directivo en el desempeño de sus funciones y responsabilidades. Estos cuestionarios abarcan una gran diversidad de actitudes, relacionadas con la percepción del superior, la tarea y el puesto de trabajo y la organización, medidas a través de escalas de tipo Likert ${ }^{1}$.

1. La escala de Likert es uno de los ítems más populares y utilizados en las encuestas, que toma su nombre de Rensis Likert (1903-1981), psicólogo estadounidense que la inventó en 1932 para medir de forma más fiel las actitudes de las personas. A diferencia de las preguntas dicotómicas con respuesta sí/no, la escala de Likert permite medir actitudes y conocer el grado de conformidad del encuestado con cualquier afirmación que se le proponga. Resulta especialmente útil emplearla en situaciones en las que se quiere que la persona matice su opinión. En este sentido, las categorías de respuesta servirán para obtener la intensidad de los sentimientos del encuestado hacia dicha afirmación. Por ejemplo, se puede utilizar para descubrir el nivel de acuerdo con una afirmación, la frecuencia con la que se realiza cierta actividad, el nivel de importancia que se atribuye a un determinado factor, la valoración de un servicio, producto o empresa, o la probabilidad de realizar una acción futura. Respecto a cuántos niveles debe tener el ítem, entre los investigadores no hay un consenso claro al respecto. Probablemente el ítem más utilizado sea el de cinco niveles, pero también se utilizan de cuatro, siete, o diez. Lo que se sabe es que añadir niveles redunda en la obtención de unas valoraciones más diversas. Por ejemplo, en un ítem de solo cinco puntos, los encuestados suelen evitar las dos opciones extremas, obteniéndose muy poca variación (es el conocido como «tendencia central»). Por otro lado, hay estudios que concluyen que a partir de ocho niveles los resultados obtenidos son los mismos que con ocho, con lo que añadir niveles no redundará en una mayor variación en los resultados. Parece, pues, que lo óptimo son los ítems con siete u ocho niveles. 
Se ha utilizado un cuestionario estructurado y cerrado, formado por cuatro bloques (adaptado de González Santa Cruz, 2012 y Robina Ramírez, 2003), y en determinadas preguntas se ha usado la escala Likert de cinco puntos: bloque I, formado por doce preguntas relacionadas con variables sobre la Administración a la que pertenece; bloque II, formado por cuatro preguntas sobre variables relacionadas con el puesto de trabajo; bloque III, integrado por cuatro preguntas relativas a variables relacionadas con el desarrollo y despliegue de habilidades personales y directivas en el desempeño de su puesto de trabajo y, finalmente, el bloque IV, formado por siete ítems sobre variables sociodemográficas. Para los bloques II y III se utilizaron un conjunto de descriptores que se han considerado adecuados al objetivo de la presente investigación.

Se ofreció a los entrevistados dos formatos de cuestionario: papel o telemático. La mayoría de los participantes optaron por el formato papel, posiblemente por la desconfianza a suministrar información personal a través de medios electrónicos o digitales. En resumen, la muestra seleccionada alcanzó un tamaño muestral 1407 encuestas, de las cuáles 1363 fueron válidas, lo que representa un error muestral del $2,62 \%$. En total se seleccionaron 97 entidades y unidades administrativas diferentes, pertenecientes tanto a servicios centrales como a servicios periféricos, elegidas específicamente con objeto de abarcar sectores diversos (administración general, sanidad, educación, investigación, seguridad, justicia, servicios sociales, vivienda y empleo, defensa, etc.), localización geográfica dispar (en la ciudad de Córdoba y en municipios de la provincia, de mayor y menor población) y dimensiones distintas (desde pequeńas organizaciones hasta macro entidades de más de 5000 empleados públicos).

Finalmente, la tasa de respuesta positiva es del $84,54 \%$. Es destacable la gran colaboración mostrada por la inmensa mayoría de responsables, llegando incluso a interesarse por los resultados que pudieran obtenerse de la investigación. El 49,23\% de la muestra corresponde a la Administración autonómica, mientras que la estatal y la local se repartían el 20,47\% y el 26,56\% respectivamente. La Administración universitaria alcanza el 3,7\%.

\section{RESULTADOS}

Los resultados se presentan agrupados en relación con las variables sociodemográficas, lo que permite obtener un perfil del empleo público de la provincia de Córdoba. También se presentan los resultados del análisis factorial respecto del desempeño del personal directivo y las características del buen/a empleado/a desde una perspectiva de género, así como de la valoración de las habilidades directivas y como personal directivo y subordinado, haciendo énfasis en las diferencias por sexo.

La tabla 5 muestra el perfil de los empleados públicos que respondieron al cuestionario: 
TABLA 5.

VARIABLES SOCIODEMOGRÁFICAS

\begin{tabular}{|c|c|c|c|c|}
\hline Variables & Mujeres & $\%$ & Hombres & $\%$ \\
\hline Sexo & 632 & 47,1 & 711 & 52,9 \\
\hline \multicolumn{5}{|l|}{ Edad } \\
\hline $18-25$ & 8 & 1,3 & 5 & 0,7 \\
\hline $26-35$ & 83 & 13,2 & 64 & 9 \\
\hline $36-45$ & 181 & 28,7 & 186 & 26,2 \\
\hline $46-55$ & 281 & 44,5 & 318 & 44,8 \\
\hline $56-65$ & 77 & 12,2 & 134 & 18,9 \\
\hline$>65$ & 1 & 0,2 & 3 & 0,4 \\
\hline
\end{tabular}

\section{Estado Civil}

\begin{tabular}{lrrrr}
\hline Soltero & 91 & 14,5 & 79 & 11,1 \\
\hline Casado & 471 & 75,2 & 594 & 83,7 \\
\hline Divorciado & 57 & 9,1 & 33 & 4,6 \\
\hline Viudo & 7 & 1,1 & 4 & 0,6
\end{tabular}

\section{Nivel Salarial}

\begin{tabular}{lrcrr}
\hline Hasta 1.000 €/Mes & 24 & 3,8 & 12 & 1,7 \\
\hline De 1.001 A 1.500 €/Mes & 277 & 43,9 & 178 & 25,2 \\
\hline De 1.501 A 2.000 €/Mes & 168 & 26,6 & 243 & 34,4 \\
\hline De 2.001 A 2.500 €/Mes & 120 & 19 & 163 & 23,1 \\
\hline De 2.501 A 3.000 €/Mes & 36 & 5,7 & 74 & 10,5 \\
\hline Más De 3.000 €/Mes & 6 & 1 & 36 & 5,1 \\
\hline Nivel De Formación & & & & \\
\hline Bachillerato O Inferior & 92 & 14,6 & 142 & 20,1 \\
\hline Formación Profesional & 127 & 20,2 & 73 & 10,3 \\
\hline Diplomado Universitario & 161 & 25,6 & 175 & 24,8 \\
\hline Licenciado Universitario & 198 & 31,5 & 235 & 33,2 \\
\hline Máster O Doctorado & 51 & 8,1 & 82 & 11,6 \\
\hline Afiliación Sindical & & & & \\
\hline Si & 181 & 29 & 256 & 36,2 \\
\hline No & 444 & 71 & 451 & 63,8 \\
\hline Formación Habilidades & & & & \\
\hline Si & 302 & 48,1 & 375 & 53,1 \\
\hline No & 326 & 51,9 & 331 & 46,9 \\
\hline
\end{tabular}

Fuente: elaboración propia. 
El perfil medio de las personas empleadas en el sector público de la provincia de Córdoba es el siguiente: presencia paritaria de mujeres y hombres, con una edad de entre 46 y 55 años, de estado civil casado mayoritariamente (cerca del 80\% del total de los entrevistados), con formación universitaria, un nivel salarial que se sitúa entre los 1000 y 2000 euros -se estima una media de 1787,5 euros/mes-, afiliación sindical relevante y formación específica en habilidades. Los salarios son relativamente medio-altos en comparación con otros sectores económicos (comercio, construcción, hostelería, etc.) y ocupaciones. Frente al salario medio bruto de 1634 euros/mes en España, se obtiene un salario neto mensual superior, algo que es valorado socialmente como aliciente, junto con la estabilidad y seguridad del empleo, para plantearse el ingreso en el sector público.

Por lo que se refiere a las diferencias por sexo, los hombres ocupan puestos de trabajo con mayor retribución que las mujeres: mientras que estas últimas presentan una retribución media de 1666,5 , la de los hombres asciende a 1895,3. Asimismo, las mujeres ocupan puestos directivos o de responsabilidad en un $42,9 \%$ frente al $55 \%$ de los hombres. Esta evidencia sugiere que las causas que explican estas diferencias hunden sus raices en mecanismos hisóricos tales como la socialización familiar y profesional, la educación, las dificultades para conciliar los roles profesionales y familiares, según la etapa del ciclo de vida, y los estereotipos aún vigentes en las organizaciones respecto a la presencia de mujeres en los puestos de alta responsabilidad.

En relación con la edad, si bien reflejan unos resultados muy semejantes, merece indicarse la mayor juventud de las mujeres en el perfil del empleo público. El predominio del intervalo 46-55 años implica una plantilla media madura, que provocará a medio plazo un fuerte proceso de jubilaciones, lo que supondrá un esfuerzo de planificación de recursos humanos muy notable con el fin de proporcionar los efectivos necesarios y adecuados.

Respecto al estado civil, con porcentajes mayoritarios similares entre mujeres y hombres, las mujeres ofrecen unos porcentajes superiores en soltera $(14,5 \%)$ y divorciada (9,1\%), en detrimento del estado civil casada $(75,2 \%$, frente al 83,7\% de los hombres). En cambio, en cuanto a formación, destaca la igualdad entre mujeres y hombres en los niveles universitarios $(57,1 \%$ frente a $58 \%$, respectivamente). Es destacable que la gran diferencia se obtiene en los niveles académicos inferiores, concretamente en el nivel formación profesional, en donde las mujeres duplican a los hombres, así como en bachillerato e inferior, en el que los hombres (20,1\%) superan claramente a las mujeres (14,6\%). Por último, destaca la mayor afiliación sindical de hombres frente a mujeres $(36,2 \%$ y $29 \%$, respectivamente). Igualmente, la formación específica en habilidades ofrece una mayor presencia en hombres respecto a las mujeres, si bien es muy destacado el alto porcentaje obtenido, lo que denota el gran interés que despierta la formación en habilidades como instrumento de mejora en el desempeño laboral en la Administración pública.

En la tabla 7 se muestra el resultado de la prueba chi-cuadrado (análisis factorial) para determinar la asociación entre las variables sociodemográficas (sexo, estado civil, edad, nivel de formación, nivel salarial, afiliación sindical y formación específica en habilidades directivas) y el tipo de Administración. 
TABLA 7.

ANÁLISIS FACTORIAL SOBRE VARIABLES SOCIODEMOGRÁFICAS

\begin{tabular}{lccccc}
\hline & \multicolumn{4}{c}{ Administración n (\%) } & \multirow{2}{*}{$\begin{array}{c}\chi^{\mathbf{2}} \text { (g.l.); } \\
\text { p-valor }\end{array}$} \\
\cline { 2 - 4 } & \multicolumn{1}{c}{ Local } & Autonómica & Estatal & Universidad & \\
\hline Sexo & & & & \\
\hline Mujer & $155 \mathrm{a}, \mathrm{b}(42,9)$ & $335 \mathrm{c}(52,4)$ & $107 \mathrm{~b}(37,2)$ & $31 \mathrm{a}, \mathrm{c}(60,8)$ & $\chi^{2}(3)=25,05 ;$ \\
\cline { 1 - 4 } Hombre & $206 \mathrm{a}, \mathrm{b}(57,1)$ & $304 \mathrm{c}(47,6)$ & $181 \mathrm{~b}(62,8)$ & $20 \mathrm{a}, \mathrm{c}(39,2)$ & $\mathrm{p}<0,001$ \\
\hline
\end{tabular}

Fuente: elaboración propia.

Del análisis de la tabla anterior se concluye que en relación con el género, hay diferencias significativas entre la Administración autonómica y la local y estatal. Para el resto de Administraciones no hay diferencias estadísticamente significativas. Se obtienen resultados significativamente superiores en la Administración local y estatal (hombre, con un $62,8 \%$ ) y la Administración autonómica y universitaria (mujer 52,4\% y $60,8 \%$, respectivamente).

Se ha realizado un ánálisis factorial en relación con la escala del desempeño del personal directivo por género, para estudiar las posibles diferencias en cada uno de los ítems. En función del género se estimó un MANOVA, bajo los supuestos de esfericidad (prueba Barlett: $\left.\chi^{2}(36)=7346,9 ; \mathrm{p}<0,001\right)$ y de homogeneidad de las matrices de varianzas-covarianzas $(\mathrm{M}$ de Box $=32,95 ; \mathrm{p}=0,654)$. En el cuestionario se formula una pregunta para que se valore la importancia que el personal directivo de su Administración da a una serie de aspectos que se han considerado relevantes en el desempeño profesional, abarcando variables como la evaluación del rendimiento, la

TABLA 8.

DESCRIPTIVO VARIABLES DESEMPEÑO DEL PERSONAL DIRECTIVO POR GÉNERO

\begin{tabular}{lcc}
\hline \multirow{2}{*}{ Variable desempeńo } & Mujer (n=632) & Hombre (n=711) \\
\cline { 2 - 3 } & Media (DT) & Media (DT) \\
\hline Información evaluación del rendimiento/desempeño & $3,26(1,26)$ & $3,12(1,23)$ \\
\hline Las críticas que hace del trabajo son constructivas & $3,25(1,14)$ & $3,15(1,12)$ \\
\hline Es competente en su materia & $3,72(1,14)$ & $3,56(1,14)$ \\
\hline Respeta la profesionalidad de los empleados & $3,66(1,17)$ & $3,55(1,18)$ \\
\hline Delega responsabilidad & $3,40(1,20)$ & $3,40(1,17)$ \\
\hline Se comporta como un compańero o compañera & $3,53(1,25)$ & $3,38(1,28)$ \\
\hline Se hace respetar por sus superiores & $3,78(1,10)$ & $3,60(1,08)$ \\
\hline Reconoce y valora el trabajo realizado & $3,56(1,24)$ & $3,46(1,24)$ \\
\hline Motiva a sus subordinados & $3,21(1,31)$ & $3,09(1,30)$ \\
\hline
\end{tabular}

Fuente: elaboración propia. 
delegación o la capacidad de motivar a los subordinados. En la tabla 8 se recojen las nueva variables consideradas, en donde se muestra el descriptivo de los ítems considerados en función del género. Los descriptivos están formados por nueve variables que se consideran representativas del desempeño profesional.

El MANOVA realizado para comparar las puntuaciones en los ítems de la escala de desempeño del personal directivo entre mujeres y hombres mostró que existen diferencias estadísticamente significativas $[\mathrm{F}$ Traza de Pillai $(9,1174)=1,98 ; \mathrm{p}=0,038$; eta $\left.^{2}=0,015\right]$ según el género. El tamaño del efecto -medio- indica que el 3,8\% de la varianza en relación con las variables de desempeńo del personal directivo es explicada por la variable género por lo que se continúa con el estudio para indagar en cuáles de los ítems se pudieron obtener las diferencias.

En los resultados de la tabla 9 se pueden ver los ANOVA de continuación para el MANOVA que establece la relación entre el género y las variables de desempeño del personal directivo. Los efectos significativos se presentan en los ítems Es competente en su materia, Se comporta como un compañero o compañera, Se hace respetar por sus superiores. Se trata de tres variables sumamente determinantes en la configuración de las habilidades directivas, como por ejemplo el liderazgo.

TABLA 9.

Contrastes univariados en las Variables de DESEMPEÑo DEL PERSONAL DiReCtivo Por GÉNERO

\begin{tabular}{llll}
\hline \multicolumn{1}{c}{ Variable desempeño } & F & p-valor & Eta $^{\mathbf{2}}$ \\
\hline Información evaluación del rendimiento/desempeño & 3,257 & 0,071 & 0,003 \\
\hline Las críticas que hace del trabajo son constructivas & 2,495 & 0,114 & 0,002 \\
\hline Es competente en su materia & 6,656 & $0,010^{*}$ & 0,006 \\
\hline Respeta la profesionalidad de los empleados & 2,435 & 0,119 & 0,002 \\
\hline Delega responsabilidad & 0,074 & 0,786 & 0 \\
\hline Se comporta como un compañero o compañera & 5,256 & $0,022^{*}$ & 0,004 \\
\hline Se hace respetar por sus superiores & 7,083 & $0,008^{* *}$ & 0,006 \\
\hline Reconoce y valora el trabajo realizado & 1,426 & 0,233 & 0,001 \\
\hline Motiva a sus subordinados & 1,912 & 0,167 & 0,002 \\
\hline
\end{tabular}

Fuente: elaboración propia.

* $\mathrm{p}<0,05 ;{ }^{* *} \mathrm{p}<0,01 ; \mathrm{Eta}^{2}$ : eta cuadrado parcial (tamaño del efecto).

Para profundizar más en estos resultados se procedió a realizar comparaciones por pares cuyos resultados se muestran en la figura 1. La principal conclusión que se obtiene es la mayor media que las mujeres reciben en las tres variables frente al hombre. Es decir, en las variables Es competente en su materia, Se comporta como un compañero o compañera y Se hace respetar por sus superiores ofrece resultados significativamente 
diferentes respecto a los hombres. Efectivamente, llama la atención los resultados respecto del personal directivo, en el que la percepción de una mayor competencia puede ser un indicador de gran consistencia en el sentido de que los mencionados avances no son resultados de "cuotas», sino de una mayor cualificación y preparación. Así mismo, podría presentar facetas diferenciadoras del estilo de dirección, en relación con el valor otorgado al compañerismo y al respeto mostrado por los superiores y en consonancia con la competencia percibida por sus subordinados, en la línea de las conclusiones de Cuadrado (2014) y Paustian-Underdahl et al. (2014).

FIGURA 1.

MEDIAS Y COMPARACIONES ENTRE MUJERES Y HOMBRES

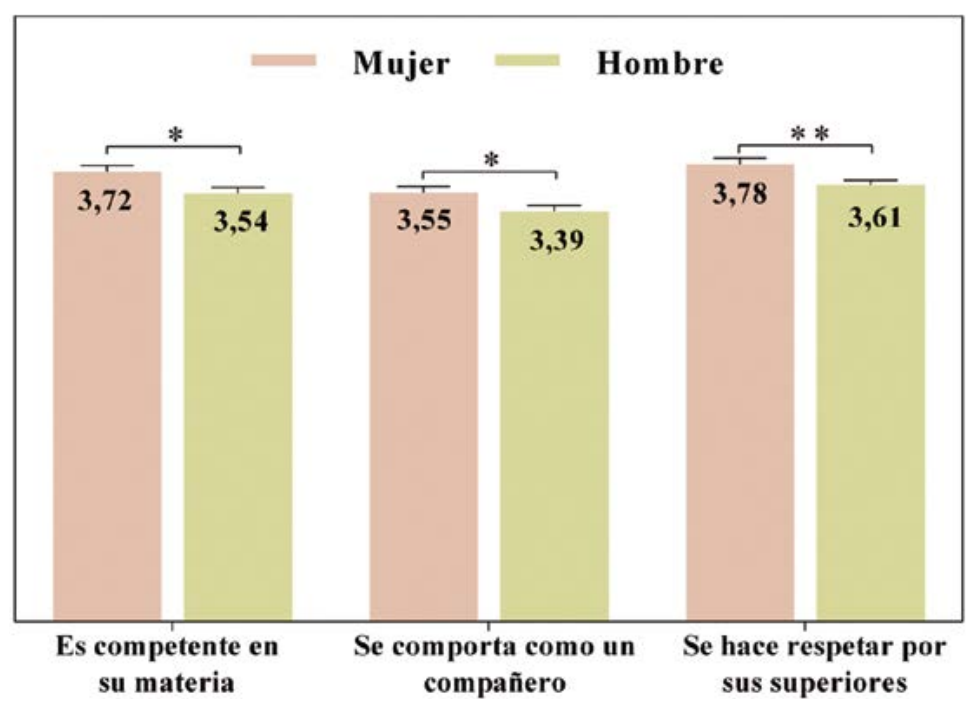

Fuente: elaboración propia.

" $\mathrm{p}<0,05 ; " \mathrm{p}<0,01$.

Continuando con el análisis, a partir de la pregunta 15 del cuestionario («Para que la Administración Pública sea eficaz, ¿̇cuáles son los atributos que debe tener «un buen empleado"? Exprese su grado de acuerdo", y sobre una escala de Likert de 1 a 5, incluyen siete característivas clave que definen el comportamiento de un empleado público. A partir de los resultados obtenidos, se procedió a la comparación de la escala características del «buen/a empleado/a» por género, que ha permitido estudiar las posibles diferencias en cada uno de los ítems en función del género, para lo cual se realizó un MANOVA bajo los supuestos de esfericidad (prueba Barlett: $\chi^{2}(21)=2277,39$; $\mathrm{p}<0,001)$ y de homogeneidad de las matrices de varianzas-covarianzas $(\mathrm{M}$ de Box $=$ $54,68 ; \mathrm{p}=0,056)$. En la tabla 10 se muestra el descriptivo de los ítems considerados en función del género: 
Habilidades directivas y diferencias de género en el sector público: el caso de Córdoba (España) 217

TABLA 10.

DESCRIPTIVO CARACTERÍSTICAS DEL «BUEN/A EMPLEADO/A» POR GÉNERO

\begin{tabular}{lcc}
\hline \multirow{2}{*}{ Característica } & Mujer $(\mathbf{n = 6 3 2})$ & Hombre $(\mathbf{n}=\mathbf{7 1 1})$ \\
\cline { 2 - 3 } & Media (DT) & Media (DT) \\
\hline Constancia & $4,39(0,83)$ & $4,30(0,77)$ \\
\hline Iniciativa & $4,33(0,86)$ & $4,17(0,89)$ \\
\hline Organización y eficacia & $4,67(0,68)$ & $4,54(0,70)$ \\
\hline Dotes de mando & $3,54(1,08)$ & $3,55(1,02)$ \\
\hline Obediencia & $3,50(1,11)$ & $3,42(1,10)$ \\
\hline Cordialidad en el trato & $4,56(0,76)$ & $4,41(0,78)$ \\
\hline Honestidad & $4,74(0,65)$ & $4,74(0,60)$ \\
\hline
\end{tabular}

Fuente: elaboración propia.

El MANOVA mostró que existen diferencias estadísticamente significativas [F Traza de Pillai $(7,1246)=4,69 ; \mathrm{p}<0,001 ;$ eta $\left.^{2}=0,026\right]$ según el género. El tamaño del efecto -medio- indica que el $2,6 \%$ de la varianza en relación con las características del «buen/a empleado/a» es explicada por la variable género, por lo que se continúa con el estudio para indagar en cuáles de los ítems se pudieron obtener las diferencias.

En los resultados de la tabla 11 se pueden ver los ANOVA de continuación para el MANOVA que establece la relación entre el género y características del «buen/a empleado/a». Los efectos significativos se presentan en los ítems Constancia, Iniciativa, Organización y eficacia y Cordialidad en el trato. Ciertamente, la Iniciativa, es un atributo que puede estar influido por la consideración de que en la función pública está «todo» regulado y prefijado, pero no es menos cierto que en todos los trabajos hay un amplio margen en el que el trabajador puede mostrar su iniciativa, para lo cual es básico y fundamental la actitud que muestra cada persona.

TABLA 11.

CONTRASTES UNIVARIADOS CARACTERÍSTICAS DEL «BUEN/A EMPLEADO/A» POR GÉNERO

\begin{tabular}{lrll}
\hline \multicolumn{1}{c}{ Característica } & F & p-valor & Eta $^{\mathbf{2}}$ \\
\hline Constancia & 4,872 & $0,027^{*}$ & 0,004 \\
\hline Iniciativa & 8,393 & $0,004^{* *}$ & 0,007 \\
\hline Organización y eficacia & 12,131 & $0,001^{* *}$ & 0,010 \\
\hline Dotes de mando & 0,008 & 0,928 & 0 \\
\hline Obediencia & 1,699 & 0,193 & 0,001 \\
\hline Cordialidad en el trato & 13,177 & $<0,001^{* *}$ & 0,01 \\
\hline Honestidad & 0,003 & 0,956 & 0 \\
\hline
\end{tabular}

Fuente: elaboración propia.

* $\mathrm{p}<0,05 ;{ }^{* *} \mathrm{p}<0,01 ;{ }^{* * *} \mathrm{p}<0,001$. 
Para profundizar más en estos resultados se procedió a realizar comparaciones por pares cuyos resultados que se muestran en la figura 2:

Figura 2.

MEDIAS Y COMPARACIONES ENTRE MUJERES Y HOMBRES

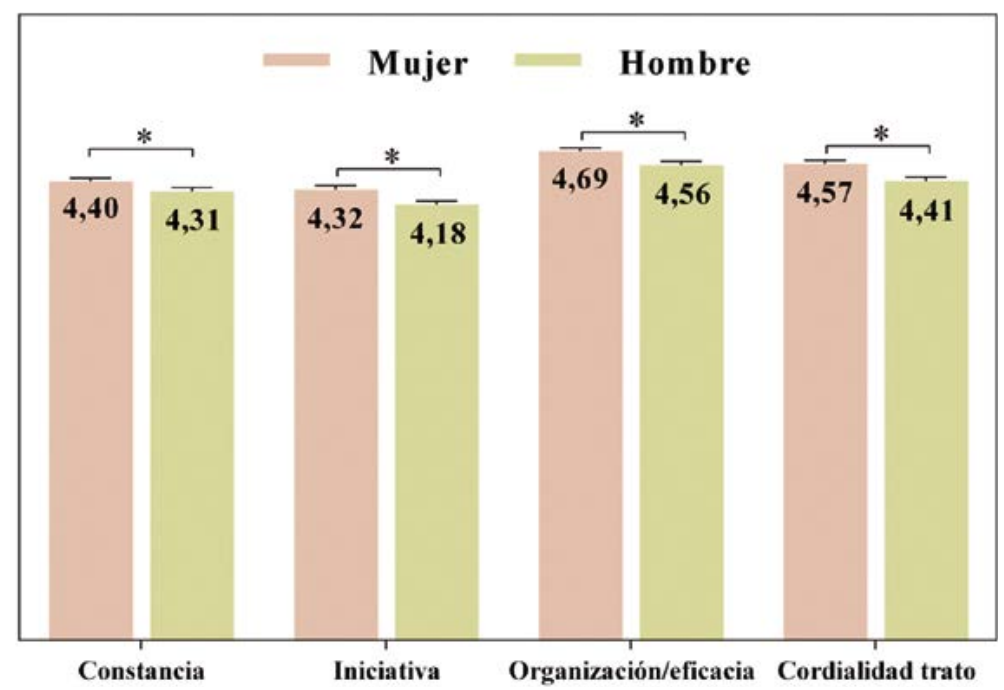

Fuente: elaboración propia.

${ }^{*} \mathrm{p}<0,05$.

En primer lugar, destaca la mayor puntuación que las mujeres otorgan a las cuatro variables consideradas respecto a los hombres, que en ambos géneros se consideran elevados. Se está ante una percepción exigente de lo que se considera un «buen/a empleado/a" público, en cuyos atributos y perfiles destacan la necesidad de ser organizados y eficaces.

Estos resultados sugieren que las personas empleadas en el sector público reconocen y valoran en primer lugar la eficacia en el desempeño profesional como el atributo más relevante. En las cuatro variables que se analizan en las que el género explica las diferencias obtenidas, resultan significativo que las mujeres otorguen una puntuación mayor en todos los casos, lo que sugiere que las mujeres presentan una mejor valoración de las habilidades directivas que los hombres.

Finalmente, se recoge la valoración realizada a un inventario de veintidós habilidades directivas por género. Se trata de un conjunto de descriptores que se consideran muy representativos de la amplia tipología de habilidades directivas. En la tabla 12 se recogen las medias de las valoraciones para cada habilidad por género y puesto de trabajo (directivo o subordinado): 
Habilidades directivas y diferencias de género en el sector público: el caso de Córdoba (España) 219

TABLA 12.

VALORACIÓN DE LAS HABILIDADES DIRECTIVAS

\begin{tabular}{lcccc}
\hline \multirow{2}{*}{ Habilidad } & \multicolumn{2}{c}{ Directivos } & \multicolumn{2}{c}{ Subordinados } \\
\cline { 2 - 5 } & Mujer & Hombre & Mujer & Hombre \\
\hline Capacidad de comunicación & 3,99 & 3,92 & 3,54 & 3,41 \\
\hline Motivación & 3,96 & 3,88 & 3,23 & 3,05 \\
\hline Liderazgo & 3,75 & 3,80 & 3,10 & 3,06 \\
\hline Colaboración y trabajo en equipo & 4,19 & 4,14 & 3,41 & 3,30 \\
\hline Creatividad & 3,70 & 3,82 & 3,17 & 2,98 \\
\hline Capacidad de aprender & 4,30 & 4,18 & 3,61 & 3,39 \\
\hline Desarrollo de la visión & 3,61 & 3,61 & 3,21 & 3,06 \\
\hline Desarrollo de personas & 3,74 & 3,61 & 3,14 & 3,00 \\
\hline Desarrollo personal & 4,01 & 3,85 & 3,19 & 3,01 \\
\hline Optimización de recursos & 3,71 & 3,71 & 3,19 & 3,17 \\
\hline Resolución de conflictos & 3,88 & 3,72 & 3,21 & 3,12 \\
\hline Inteligencia emocional & 3,94 & 3,66 & 3,16 & 3,02 \\
\hline Gestión de estrés & 3,51 & 3,56 & 3,24 & 3,01 \\
\hline Gestión del tiempo & 3,73 & 3,61 & 3,31 & 3,11 \\
\hline Res. problemas y toma de decisiones & 4,01 & 3,99 & 3,50 & 3,27 \\
\hline Negociación & 3,80 & 3,79 & 3,31 & 3,09 \\
\hline Gestión de reuniones & 3,61 & 3,58 & 3,21 & 3,01 \\
\hline Delegación & 3,67 & 3,59 & 3,24 & 3,04 \\
\hline Asertividad & 3,76 & 3,71 & 3,24 & 3,10 \\
\hline Presentaciones en público & 3,51 & 3,69 & 3,46 & 3,27 \\
\hline Gestión del talento & 3,61 & 3,61 & 3,06 & 2,95 \\
\hline Coaching & 3,35 & 3,44 & 2,93 & 2,83 \\
\hline
\end{tabular}

Fuente: elaboración propia.

La valoración de las habilidades directivas que diferecian entre mujeres y hombres, en puestos directivos y subordinados, ofrece algunas semejanzas de gran interés: mientras que a nivel de directivos la capacidad de aprender es la habilidad más destacada entre mujeres y hombres ( 4,30 y 4,18 sobre 5 , respectivamente), a nivel de subordinados las mujeres vuelve a considerar la capacidad de aprender como la habilidad más valorada $(3,61)$, mientras que los hombres valoran la colaboración y el trabajo en equipo como la habilidad directiva más destacada en sus responsables. El inventario de veintidós habilidades muestra una gran semejanza en las valoraciones entre mujeres y hombres, lo que refuerza la idea de la transversalidad de las habilidades como predictor del desempeño con independencia del sexo. 
Clasificando las habilidades en tres grandes grupos (personales, interpersonales y de dirección de personas), obtenemos unos resultados que muestran en primer lugar que las habilidades de dirección de personas son las que peor valoración reciben, tanto en mujeres como en hombres, sean directivos (3,69 de media, tanto en mujeres como hombres) o subordinados (3,16 en mujeres y 3,04 en hombres). En cambio, las habilidades personales e interpersonales reciben una mejor valoración, destacándose que son las mujeres las que otorgan una mejor valoración $(3,87$ y 3,83 como directivos, respectivamente, y 3,31 y 3,33 como subordinados). En cambio, los hombres (directivos) otorgan una valoración de 3,78 tanto en habilidades personales e interpersonales, mientras que como subordinados se reducen a 3,12 (habilidades personales) y 3,16 (habilidades interpersonales).

\section{CONCLUSIONES}

En la actualidad, un análisis integral de cualquier entorno empresarial y del sector público que sea especialmente relevante debe incorporar la perspectiva de género como un eje central que atraviesa toda la organización y genera múltiples efectos (Alvesson y Billing, 1997). Son muchos los argumentos que pueden utilizarse, entre los que cabe destacar, en primer lugar, el interés humanitario por luchar contra una injusticia social basada en la discriminación por género (Pastor, 1999). En cambio, hay otras razones relativas a la necesidad de aprovechar el potencial y el talento de los recursos humanos ofrecidos por muchas mujeres, bien preparadas profesionalmente y equipadas con suficientes competencias directivas.

El perfil del empleo público de la provincia de Córdoba viene determinado por una presencia paritaria de mujeres y hombres, con una edad comprendida entre 46 y 55 años y con mayor juventud en las mujeres. En cuanto al estado civil predomina el casado (cerca del 80\%), y los hombres muestran una mayor estabilidad familiar. La formación universitaria (cerca del 60\%) es similar entre mujeres y hombres, si bien en niveles académicos inferiores las diferencias son muy notables. El nivel salarial se sitúa entre los 1000 y 2000 euros, aunque las mujeres ocupan puestos con menor retribución, pues alcanzan un nivel salarial medio de 1666 euros frente a los 1895 euros de los hombres. La afiliación sindical es significativa, con niveles que en los hombres alcanza el 36,6\%. También es notable la formación en habilidades.

Se ha constatado, en relación con la escala del desempeño del personal directivo por género, que en las variables Es competente en su materia, Se comporta como un compañero o compañera y Se hace respetar por sus superiores las mujeres obtienen resultados significativamente diferentes respecto a los hombres, confirmándose así investigaciones como la de Strebler et al. (1997), lo que dice mucho a favor de los avances que se están produciendo en el ámbito de la igualdad de género, en consonancia con Lupano Perugini y Castro Solano (2010), para quienes las personas tienden a creer que para desempeñarse efectivamente en puestos de liderazgo es necesario desplegar cualidades masculinas. Dicha percepción ha presionado a muchas mujeres a adoptar características similares a los hombres. 
La comparación por género de la escala sobre características del «buen/a empleado/a», permite concluir que la importante y creciente presencia de mujeres en el sector público está incorporando una buena dosis de constancia y cordialidad en el trato, lo que podría explicar dichas diferencias y elevada consideración como atributos del «buen/a empleado/a», mientras que que la «iniciativa» es el atributo que menor puntuación se le otorga, aunque dentro de un nivel elevado. Esta cuestión apunta a las habilidades de gestión de la casa y de la familia que las mujeres aplican al funcionamiento empresarial (Rebollo Catalán et al., 2016).

Respecto a la percepción de un total de veintidós habilidades directivas, la investigación concluye que la capacidad de aprender es la habilidad mejor valorada, tanto por mujeres como por hombres que ocupan puestos directivos, dándose una valoración media superior cuando los directivos se autovaloran que cuando son valorados por sus subordinados, cuestión que parece obvia desde la perspectiva psicológica, dado que las personas tienden a valorarse mejor que como les ven los demás, y más aún en un ámbito tan especial como es el del trabajo, en el que aceptar y reconocer una actuación deficiente puede significar la desaprobación al desempeño realizado. En cambio, en cuanto a colaboración y trabajo en equipo como habilidad directiva, de conformidad con Letelier Gamboa (2014), las mujeres, tanto directivas como subordinadas, presentan una mejor valoración.

A nivel de subordinados hay diferencias en la valoración entre mujeres y hombres, y se obtienen valoraciones muy discretas en muchas habilidades, en la línea de lo apuntado por Barbuto et al. (2007), así como una desviación típica elevada, lo que refuerza la idea de que existen directivos eficientes (líderes) y malos directivos (tóxicos). La mejor valoración alcanzada en habilidades personales e interpersonales -más destacada en mujeres que en hombres, en coincidencia con Burke y Collins (2001) frente a las de dirección de personas, refuerza la idea de que la estrategia más urgente debe apuntar hacia la capacidad de dirigir personas, en la línea de las investigaciones de Goleman (1996). Esta importancia de la capacidad de aprender, en consonancia con King (2015), apunta a la necesidad de aprovechar el talento de de una sociedad, y una organización que únicamente aprovecha la mitad de las personas con talento, está reduciendo su potencial de crecimiento.

Se constata también que las valoraciones de las mujeres sobre las mujeres directivas son más positivas que las de los hombres, perspectiva que es coinicente con las aportaciones de Moncayo Orjuela y Zuluaga (2015) en el sentido de que las mujeres ofrecen nuevas alternativas y propuestas organizacionales que resultan ser mejores que los esquemas masculinos tradicionales en declive. Los hombres siguen teniendo una visión estereotipada de los directivos, a la vez que que dudan de la capacidad de dirección de las mujeres, en la línea de lo apuntado por Caro González et al. (2007). Estos y otros resultados obtenidos permiten orientar las políticas de desarrollo de competencias hacia la mejora de las habilidades directivas de las mujeres como una estrategia decidida de empowerment, que haga realidad los sinceros deseos de igualdad con los hombres en el acceso a puestos de responsabilidad, y que permitirá romper el denominado «techo de cristal», haciendo visible a la mujer en puestos directivos. 
Como futura línea de investigación se considera relevante profundizar la influencia del género en el perfil profesional de las personas que deciden integrase en el sector público, buscando diferencias significativas por actividad o por Administración de pertenencia. Es relevante profundizar en las relaciones existentes entre genero y desarrollo de habilidades, matizando las percepciones a nivel de dirección o subordinado, así como por edad y sexo. Así mismo, las conclusiones podrían aplicarse en otros contextos geográficos locales, provinciales, autonómicos, e incluso nacionales e internacionales, que permitan comparaciones y análisis longitudinales; y también sociales, que indaguen en las diferencias entre colectivos (por edad, razón social, profesión, etc.) y entre culturas. Las aportaciones de estas investigaciones serán sumamente interesantes en el avance del conocimiento sobre un aspecto de gran actualidad, lo que favorecerá la toma de decisiones en muchos ámbitos, especialmente en lo referente a la política de selección y formación, así como en aspectos de tanta importancia como la cobertura de puestos directivos o de responsabilidad.

Finalmente, cabe señalar que para el avance en la investigación sobre las habilidades directivas en el sector público desde una perspectiva de género, sería deseable un mayor conocimiento de investigaciones más sectoriales que permitan un mejor conocimiento en contextos específicos en donde la mayor o menor presencia de mujeres y hombres permitan el establecimiento de políticas específicas de desarrollo de los recursos humanos. Como complemento a esta estrategia, la política de formación deberá enfatizar de una manera continua el despliegue y valoración del mérito para el acceso en puestos de mayor responsabilidad como un eficaz instrumento para desarrollar una verdadera política de igualdad que facilite el acceso de las mujeres a puestos de responsabilidad.

Por otra parte, desde el punto de vista de la percepción de las habilidades personales y directivas, sería conveniente avanzar en el conocimiento de las diferencias entre mujeres y hombres para determinar qué habilidades muestran una mayor capacidad predictiva sobre el grado de desempeño de los empleados y sobre aspectos estratégicos de la organización.

\section{Referencias}

Alas, Ruth. 2007. «The impact of employee participation on job satisfaction during change process", Problems and Perspectives in Management, 5 (4): 28-33.

Alvesson, Mats y Yvonne Due Billing. 1997. Understanding gender and organizations. Londres: Sage.

Ballart, Xavier. 2010. «Una presa difícil de atrapar: el rendimiento de gobiernos y administraciones públicas», Revista Española de Ciencia Política, 22: 9-26.

Barberá Heredia, Esther. 2004. «Diversidad de género, igualdad de oportunidades y entornos laborales», CIRIEC-España, revista de economía pública, social y cooperativa, 50: 37-53.

Barberá Heredia, Esther, Amparo Ramos López y Carlos Candela Agulló. 2011. «Laberinto de cristal en el liderazgo de las mujeres», Psicothema, 23 (2): 173-179. 
Barbuto, John E., Susan Fritz, Gina S. Matkin y David B. Marx. 2007. «Effects of Gender, Education, and Age upon Leaders' Use of Influence Tactics and Full Range Leadership Behaviors», Sex Roles, 56: 71-83. Disponible en: https://doi. org/10.1007/s11199-006-9152-6.

Berbel Sánchez, Sara. 2014. «Liderazgo y género: Análisis de las divergencias conceptuales y sus efectos en la teoría y práctica feminista», Quaderns de Psicologia, 16 (1): 73-84.

Bieger, Sara. 2005. «La mujer directiva vista por los hombres y por las mujeres», en Estudio sobre habilidades directivas en la mujer. Madrid: Comunidad de Madrid.

Burke, Sarah y Karen M. Collins. 2001. «Gender differences in leadership styles and management skills», Women in Management Review, 16 (5): 244-257. Disponible en: https://doi.org/10.1108/09649420110395728.

Caro González, Francisco J., María del Mar García Gordillo, Carlos J. Rodríguez Rad y Gloria Jiménez Marín. 2007. «Percepción de las habilidades y aceptación de las mujeres directivas en las empresas de comunicación», Zer, 22: 253-266.

Comisión Europea. 2012. Base de datos sobre hombres y mujeres en la toma de decisiones. Disponible en: https://goo.gl/4k1h6d.

Courtney Droms, Hatch y K. Stephen Sheryl-Ann. 2015. "Gender Effects on Perceptions of Individual and Corporate Social Responsibility", Journal of Applied Business and Economics, 17(3): 63-71.

Cuadrado, Isabel, María Soledad Navas y Fernando Molero Alonso. 2004. «El acceso de las mujeres a puestos directivos: género, contexto organizacional y estilos de liderazgo", Revista de Psicología General y Aplicada, 57 (2): 181-192.

Cuadrado, Isabel. 2014. «Do women and men adopt different leadership styles? An analysis of the influence of leadership styles on access to managerial positions», International Journal of Social Psychology, 18 (3): 283-307.

De la Cruz, Silvia. 2006. "Análisis de la relación: la mujer en la educación y el trabajo", Fundamentos en Humanidades, 7 (13-14): 271-292.

Eagly, A., y B. Johnson. 1990. «Gender and leadership style: A meta-analysis», Psychological Bulletin, 108: 233-256.

Gibson, James, John M. Ivancevich y James H. Donnlley. 2001. Las organizaciones. Santiago de Chile: McGraw-Hill.

Giddens, Anthony. 2001. Sociología. Madrid: Alianza editorial.

Goleman, Daniel. 1996. Inteligencia emocional. Barcelona: Editorial Kairós.

González Santa Cruz, Francisco. 2012. Satisfacción laboral y compromiso organizativo. Estudio aplicado al sector hotelero de la provincial de Córdoba [tesis doctoral]. Córdoba: Universidad de Córdoba.

Instituto Nacional de Estadística. 2016a. INEbase. Demografía y población. Cifras de población. Censos demofiguras. Disponible en: https://goo.gl/N3kzWq.

Instituto Nacional de Estadística. 2016b. INEbase. Cuentas Económicas. Contabilidad Regional de España. Disponible en: https://goo.gl/5ZqSMA.

Instituto Nacional de Estadística. 2016c. Informe del mercado de trabajo de Córdoba. Madrid: Servicio Público de Empleo Estatal. 
Jonsen, Karsten y Martha L. Mazneuski. 2010. "Gender differences in leadership. Believing is seeing: Implications for managing diversity», Equality, Diversity and Inclusion: An International Journal, 29(6): 549-572. Disponible en: https://doi. org/10.1108/02610151011067504.

Kabacoff, Robert I. 1998. «Gender differences in organizational leadership: A large simple study», en Annual American Psychological Association Convention. San Francisco.

King, Dominic. 2015. Mujeres directivas: en el camino hacia la alta dirección, Grant Thornton International Business Report. Disponible en: https://goo.gl/1U9tJT.

Letelier Gamboa, Cristina. 2014. «Diferencias de género en los estilos de afrontamiento de conflictos de funcionarios de un servicio de salud pública Viña del Mar-Quillota», Revista de Psicología. Universidad Viña del Mar, 3 (6): 64-80.

Lombardo, Emanuela y Mieke Verloo. 2010. «La "interseccionalidad" del género con otras desigualdades en la política de la Unión Europea», Revista Española de Ciencia Política, 23: 11-30.

Lupano Perugini, María Laura y Alejandro Castro Solano. 2010. «Análisis de características estereotípicas de género en líderes y seguidores», SUMMA Psicológica UST, 7 (2): 55-66.

Ministerio de Hacienda y Administraciones Públicas. 2016. Boletín Estadístico del Personal al Servicio de las Administraciones Públicas. Registro Central de Personal, enero.

Molero Alonso, Fernando. 2009. Mujer y liderazgo en el siglo XXI: una aproximación psicosocial a los factores que dificultan el acceso de la mujer a los puestos de alta responsabilidad. Madrid: Instituto de la Mujer. Disponible en: https://goo.gl/SdiXjN.

Moncayo Orjuela, B. C. y Carlos Eduardo Villalba Gómez. 2013. "Estereotipos de género y liderazgo", en XVIII Congreso Internacional de Contaduría, Administración e Informática, octubre de 2013. México: Ciudad Universitaria.

Moncayo Orjuela, Bibiana Carolina y David Zuluaga. 2015. «Liderazgo y género: barreras de mujeres directivas en la academia", Pensamiento y Gestión, 39: 142-177.

Munduate, Lourdes. 2003. "Gender and leadership. Differences between women's and men's access to managerial positions», International Journal of Social Psychology, 18 (3): 309-314.

Organización Internacional del Trabajo y Programa de las Naciones Unidas para el Desarrollo-OIT-PNUD. 2009. Trabajo y familia: hacia nuevas formas de conciliación con corresponsabilidad social. Santiago de Chile.

Organización Internacional del Trabajo (OIT). 2003. ILO Declaration on Fundamental Principles and Rights at Work. Genève: International Labour Organization. Disponible en: https://goo.gl/esuxbh.

Pastor, Rosa. 1999. «Aspectos psicosociales de la asimetría genérica: rupturas, cambios y posibilidades», en J. Fernández (coord.), La intervención en los ámbitos de la sexología y la generología. Madrid: Pirámide.

Paustian-Underdahl, Samantha C. Lisa Slattery Walker y David J. Woehr. 2014. "Gender and Perceptions of Leadership Effectiveness: A Meta-Analysis of Contextual Moderators", Journal of Applied Psychology, 99 (6): 1129-1145. Disponible en: http://dx.doi.org/10.1037/a0036751. 
Peters, Thomas J. y Robert H. Waterman. 1982. En busca de la excelencia. Barcelona: Ediciones Folio.

Rebollo Catalán, María Ángeles, Rosario Rodríguez Díaz y Rocío Jiménez Cortés. 2016. "Gestión y liderazgo empresarial con perspectiva de género: voces y experiencias", Cuestiones de Género: de la Igualdad y la Diferencia, 11: 329-350.

Robina Ramírez, Rafael. 2002. Condicionantes sociolaborales de los empleados públicos. Motivación y satisfacción laboral en la Administración Regional Extremeña [tesis doctoral]. Universidad de Extremadura.

Rosa Navarro, María Dolores de la y Antonio Carmona Lavado. 2010. «Cómo afecta la relación del empleado con el líder a su compromiso con la organización», Universia Business Review, 26: 112-132.

Rubin, Gayle. 1986. «El tráfico de mujeres: notas sobre la «economía política» del sexo", Nueva antropología, 8 (30): 95-145.

Sánchez-Apellániz, Mercedes. 1997. Mujeres, dirección y cultura organizacional. Madrid: Centro de Investigaciones Sociológicas.

Stoller, Robert. 1968. Sex and gender. On the development of masculinity and femininity. New York: Science House.

Strebler, Marie, D. Robinson y P. Heron. 1997. Getting the Best Out of Competencies. Brighton: Institute of Employment Studies Report.

Werther, Willian B. y Keith Davis. 2008. Administración de recursos humanos. El capital humano de las empresas. México: McGraw-Hill/Interamericana editores.

Whetten, David y Kim Cameron. 2005. Developing Management Skills. Pearson: Prentice Hall.

Wood, Julia T. 1992. "Moving from woman's nature to standpoint epistemology", Women's Studies in Communication, 22: 1-24. Disponible en: https://doi.org/10.1 080/07491409.1992.11089757.

\section{ANEXO}

Preguntas fundamentales del Cuestionario

P (13). Díganos por favor, en el desempeño de su puesto de trabajo ¿Qué grado de cumplimiento tiene con los siguientes aspectos?

\begin{tabular}{ll|l|l|l|l|l|}
\hline & \multicolumn{2}{c}{$\begin{array}{c}\text { Total } \\
\text { desacuerdo }\end{array}$} & \multicolumn{3}{r}{$\begin{array}{r}\text { Total } \\
\text { acuerdo }\end{array}$} \\
\cline { 5 - 7 } & & $\mathbf{1}$ & $\mathbf{2}$ & $\mathbf{3}$ & $\mathbf{4}$ & $\mathbf{5}$ \\
\hline $\mathbf{1}$ & Favorece el trabajo en equipo & & & & & \\
\hline $\mathbf{2}$ & Permite la introducción de ideas propias (Iniciativa) & & & & \\
\hline $\mathbf{3}$ & Es variado e interesante & & & & & \\
\hline $\mathbf{4}$ & Permite la participación en las decisiones & & & & \\
\hline $\mathbf{5}$ & Se actualiza a lo largo del tiempo (formación) & & & & & \\
\hline
\end{tabular}




\begin{tabular}{|c|c|c|c|c|c|c|}
\hline & & \multicolumn{3}{|c|}{$\begin{array}{l}\text { Total } \\
\text { desacuerdo }\end{array}$} & \multicolumn{2}{|c|}{$\begin{array}{r}\text { Total } \\
\text { acuerdo }\end{array}$} \\
\hline & & 1 & 2 & 3 & 4 & 5 \\
\hline 6 & Permite identificarse con su Administración pública & & & & & \\
\hline 7 & Permite conciliar la vida laboral y familiar & & & & & \\
\hline 8 & Ayuda a mejorar el servicio público & & & & & \\
\hline
\end{tabular}

P (14). Valore la importancia que el personal directivo de su Administración da a los siguientes aspectos:

\begin{tabular}{ll|l|l|l|l|l|}
\hline & & \multicolumn{2}{c}{$\begin{array}{c}\text { Total } \\
\text { desacuerdo }\end{array}$} & \multicolumn{3}{c}{$\begin{array}{c}\text { Total } \\
\text { acuerdo }\end{array}$} \\
\cline { 5 - 7 } & & $\mathbf{1}$ & $\mathbf{2}$ & $\mathbf{3}$ & $\mathbf{4}$ & $\mathbf{5}$ \\
\hline $\mathbf{1}$ & $\begin{array}{l}\text { Información sobre los resultados de la evaluación del } \\
\text { rendimiento/desempeño }\end{array}$ & & & & \\
\hline $\mathbf{2}$ & Las críticas que hace del trabajo son constructivas & & & & & \\
\hline $\mathbf{3}$ & Es competente en su materia & & & & \\
\hline $\mathbf{4}$ & Respeta la profesionalidad de los empleados & & & & \\
\hline $\mathbf{5}$ & Delega responsabilidad & & & & & \\
\hline $\mathbf{6}$ & Se comporta como un compañero & & & & \\
\hline $\mathbf{7}$ & Se hace respetar por sus superiores & & & & & \\
\hline $\mathbf{8}$ & Reconoce y valora el trabajo realizado & & & & \\
\hline $\mathbf{9}$ & Motiva a sus subordinados & & & & & \\
\hline
\end{tabular}

P (15). Para que la Administración pública sea eficaz, ¿̨cuáles son los atributos que debe tener «un buen empleado»? Exprese su grado de acuerdo:

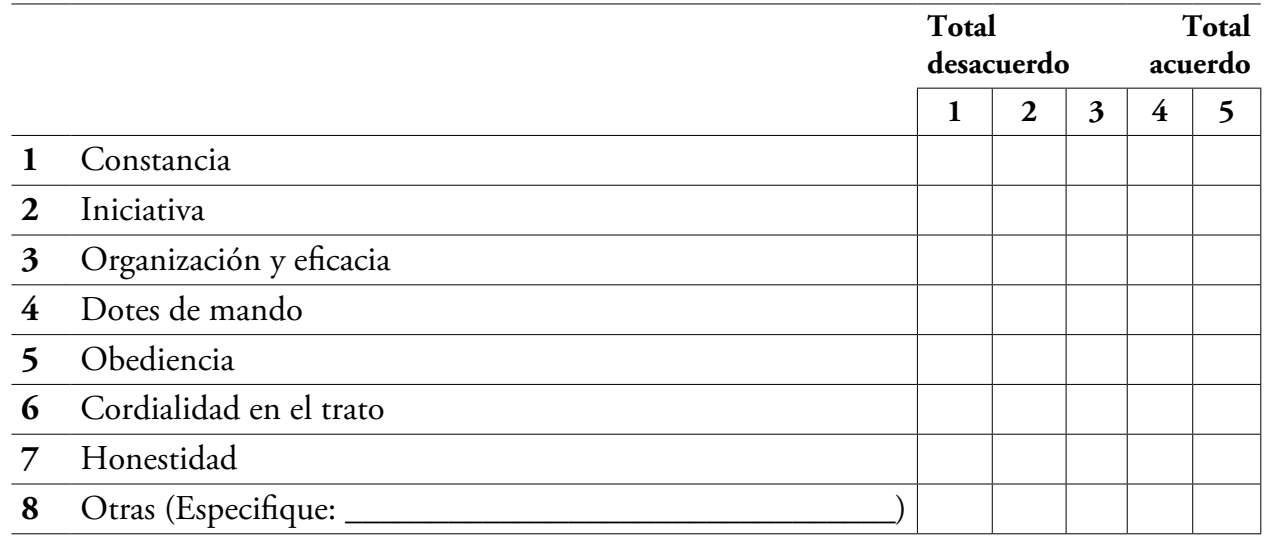


Habilidades directivas y diferencias de género en el sector público: el caso de Córdoba (España) 227

$P$ (17). Si usted desarrolla un puesto de trabajo en el que tenga personal a su cargo, valore cómo percibe sus propias habilidades directivas en:

$P$ (18). Si usted desarrolla un puesto de trabajo en el que no tenga personal a su cargo, valore cómo percibe Usted las habilidades directivas de sus responsables en:

\begin{tabular}{|c|c|c|c|c|c|c|}
\hline & \multicolumn{5}{|c|}{$\begin{array}{lr}\text { Nada } & \text { Muy } \\
\text { desarrollada } & \text { desarrollada }\end{array}$} \\
\hline & & 1 & 2 & 3 & 4 & 5 \\
\hline 1 & $\begin{array}{l}\text { Capacidad de comunicación (Habilidad para expresar, } \\
\text { escuchar e intercambiar información y opiniones necesarias para } \\
\text { el trabajo con sus responsables y subordinados) }\end{array}$ & & & & & \\
\hline 2 & $\begin{array}{l}\text { Motivación (Capacidad para utilizar nuestro potencial, ser } \\
\text { aplicados y tenaces, y no dejarnos llevar por el desánimo } \\
\text { (automotivación) y para impulsar a otras personas a actuar de } \\
\text { una forma concreta) }\end{array}$ & & & & & \\
\hline 3 & $\begin{array}{l}\text { Liderazgo (Capacidad de influir en otros y apoyarlos para que } \\
\text { trabajen con entusiasmo en el logro de objetivos comunes) }\end{array}$ & & & & & \\
\hline 4 & $\begin{array}{l}\text { Colaboración y trabajo en equipo (Capacidad de trabajary } \\
\text { hacer que los demás trabajen, mediante el compromiso, la } \\
\text { implicación y la colaboración para alcanzar objetivos compartidos) }\end{array}$ & & & & & \\
\hline 5 & $\begin{array}{l}\text { Creatividad (Capacidad de encontrar formas diferentes de hacer } \\
\text { las cosas o nuevas soluciones para problemas habituales) }\end{array}$ & & & & & \\
\hline 6 & $\begin{array}{l}\text { Capacidad de aprender (Actitud de apertura a los cambios, al } \\
\text { aprendizaje y su puesta en práctica al servicio de nuestros } \\
\text { objetivos y los de la organización) }\end{array}$ & & & & & \\
\hline 7 & $\begin{array}{l}\text { Desarrollo de la visión (Capacidad de definir el camino al } \\
\text { cual se dirige la organización a largo plazo y sirve de rumbo para } \\
\text { orientar las decisiones estratégicas de crecimiento y de } \\
\text { competitividad) }\end{array}$ & & & & & \\
\hline 8 & $\begin{array}{l}\text { Desarrollo de personas (Capacidad de mejorar el aprendizaje } \\
\text { y el crecimiento de los demás a partir de un apropiado análisis de } \\
\text { sus necesidades y de la organización) }\end{array}$ & & & & & \\
\hline 9 & $\begin{array}{l}\text { Desarrollo personal (Desde una autocritica permanente, } \\
\text { capacidad de evaluar con frecuencia y profundidad el propio } \\
\text { comportamiento, reconociendo tanto los aciertos como los errores } \\
\text { personales) }\end{array}$ & & & & & \\
\hline
\end{tabular}


... $/ \ldots$

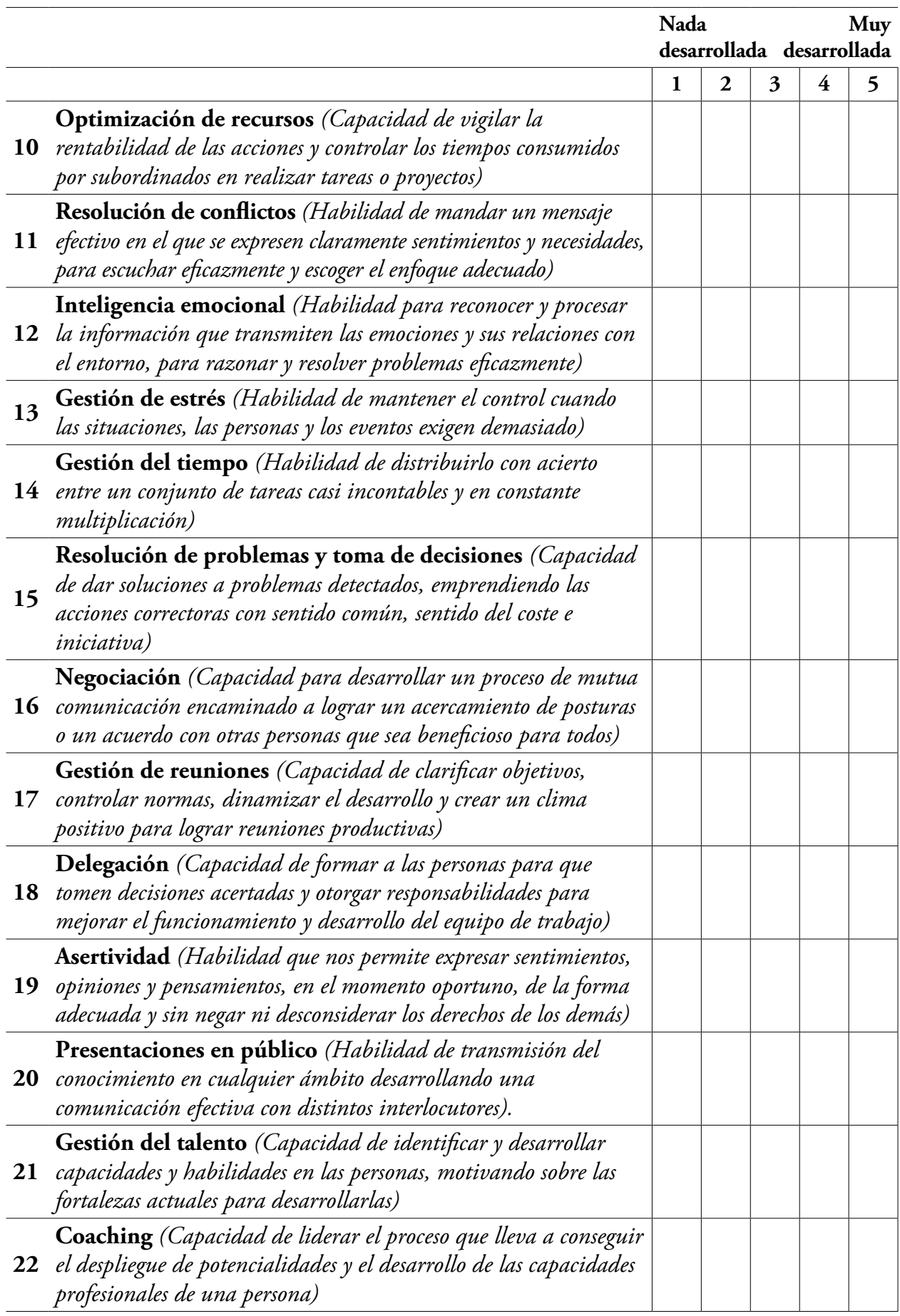


P (19). Ordene de mayor a menor importancia las cinco habilidades personales y directivas que considere más relevantes $\left(1 .^{a}, 2 .^{a}, 3 .^{a}, 4 .^{a}\right.$ y $\left.5 .^{a}\right)$ :

\begin{tabular}{l|l|l|l|}
\hline $\mathbf{1}$ & Capacidad de comunicación & $\mathbf{1 2}$ Inteligencia emocional & \\
\hline $\mathbf{2}$ & Motivación & $\mathbf{1 3}$ Gestión de estrés & \\
\hline $\mathbf{3}$ & Liderazgo & $\mathbf{1 4}$ Gestión del tiempo & \\
\hline $\mathbf{4}$ Colaboración y trabajo en equipo & $\mathbf{1 5}$ Resolución de problemas y toma de decisiones & \\
\hline $\mathbf{5}$ Creatividad & $\mathbf{1 6}$ Negociación & \\
\hline $\mathbf{6}$ & Capacidad de aprender & $\mathbf{1 7}$ Gestión de reuniones & \\
\hline 7 & Desarrollo de la visión & $\mathbf{1 8}$ Delegación & \\
\hline $\mathbf{8}$ & Desarrollo de personas & $\mathbf{1 9}$ Asertividad & \\
\hline $\mathbf{9}$ Desarrollo personal & $\mathbf{2 0}$ Presentaciones en público & \\
\hline $\mathbf{1 0}$ Optimización de recursos & $\mathbf{2 1}$ Gestión del talento & \\
\hline $\mathbf{1 1}$ Resolución de conflictos & $\mathbf{2 2}$ Coaching & \\
\hline
\end{tabular}

P (20). ¿Considera que una mayor y mejor consideración de las habilidades directivas y personales tendrían influencia positiva para la Administración?

\begin{tabular}{ccccc}
$\begin{array}{l}\text { Total } \\
\text { desacuerdo }\end{array}$ & \multicolumn{2}{r}{$\begin{array}{r}\text { Total } \\
\text { acuerdo }\end{array}$} \\
\hline 1 & 2 & 3 & 4 & 5
\end{tabular}

$1 \quad$ En el clima organizacional

2 En la mejora de la eficacia y eficiencia

3 En la valoración y percepción de los ciudadanos

4 En la motivación y satisfacción de los empleados públicos

5 En la selección de los empleados públicos

$\mathbf{6}$ En los resultados alcanzados

Presentado para evaluación: 19 de octubre de 2016.

Aceptado para publicación: 26 de febrero de 2018.

FRANCISCO J. PEREDA-PÉREZ

td1pepef@uco.es

Profesor asociado del Área de Organización de Empresas de la Universidad de Córdoba (España). Es licenciado en Ciencias Económicas y Empresariales por la Universidad Pontificia de Comillas (España). MBA por la Escuela Europea de Negocios. Es doctor en Ciencias Jurídicas y Empresariales por la Universidad de Córdoba. Experiencia 
profesional de más de treinta años en entidades públicas y privadas en ámbitos de responsabilidad en áreas de organización y recursos humanos. Ha publicado recientemente en revistas como Intangible Capital, Noésis y la Revista de Estudios Regionales. Autor de varios capítulos en libros titulados: Auditoría sociolaboral; España en la Unión Europea: más allá del Euro, y España en la CEE: del Acta Única Europea al Tratado de Maastricht. Sus principales líneas de investigación se centran en el ámbito de la gestión de los recursos humanos (auditoría, habilidades directivas, gestión estratégica) en el sector público.

\section{TOMÁS LÓPEZ-GUZMAN}

tomas.lopez@uco.es

Profesor del Área de Economía Aplicada de la Universidad de Córdoba (Espańa). Es licenciado en Derecho por la Universidad de Granada (España) y licenciado en Ciencias Económicas y Empresariales y doctor en Economía por la UNED. Es autor de más de cien artículos publicados en revistas científicas de diferentes países. Entre otras revistas ha publicado en International Journal of Contemporary Hospitality Research, Current Issues in Tourism, Tourism, Journal of Intellectual Capital, Journal of Tourism and Heritage Cultural, Journal of Tourism and Development, Tourism and Hospitality Management, Anatolia, African Journal of Business Research, British Food Journal o Tourism Management Studies. También es autor de más de veinte capítulos de libros y de dos libros. Asimismo, ha sido investigador principal en nueve proyectos de investigación financiados en convocatorias públicas y como investigador ha participado en más de diez proyectos de investigación, también financiados en diferentes convocatorias públicas. Ha realizado estancias de investigación en diferentes países europeos (Portugal, Reino Unido, Bélgica, Francia, Italia, Bulgaria, Polonia, Dinamarca y República Checa), latinoamericanos (Chile, México, Uruguay, El Salvador y Nicaragua) y africanos (Cabo Verde), financiadas por organismos públicos españoles y extranjeros. Sus principales líneas de investigación son la economía del turismo y el medio ambiente. En la actualidad, sus investigaciones están centradas en el análisis de los destinos turísticos, en el impacto del turismo en el medio ambiente y en el turismo comunitario.

\section{FRANCISCO GONZÁLEZ-SANTA CRUZ}

francisco.gonzalez@uco.es

Licenciado en Ciencias del Trabajo por la Universitat Oberta de Catalunya, diplomado en Relaciones Laborales y doctor en Ciencias Jurídicas y Empresariales por la Universidad de Córdoba. Es profesor ayudante doctor del Área de Organización de Empresas de la Universidad de Córdoba. Es autor de más de veinte artículos científicos, entre los que destacan los publicados en las revistas Journal of Human Resources in Hospitality and Tourism, Tourism Management Perspectives, Journal of Heritage Tourism, Sustainability o International Journal of Hospitality and Tourism Administration. Sus principales líneas de investigación se refieren a la investigación social en el ámbito turístico y la gestión estratégica de los recursos humanos. 